\title{
Is the Two-Color Method Superior to Empirical Equations in Refractive Index Compensation?
}

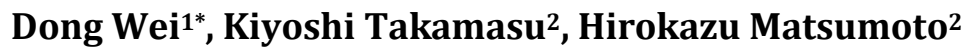 \\ ${ }^{1}$ Department of Mechanical Engineering, Nagaoka University of Technology, Nagaoka City, Japan \\ ${ }^{2}$ Department of Precision Engineering, The University of Tokyo, Tokyo, Japan \\ Email: *weidong@mech.nagaokaut.ac.jp
}

Received 6 April 2016; accepted 19 August 2016; published 25 August 2016

\begin{abstract}
The Edlén empirical equations and the two-color method are the commonly used approaches to converting a length measured in air to the corresponding length in vacuum to eliminate the influence of the refractive index of air. However, it is not well known whether the two-color method is superior to empirical equations in refractive index compensation. We investigated the uncertainties of these approaches via numerical calculations of their sensitivity coefficients of environmental parameters. On the basis of a comparison of their uncertainties, we found that in a $0 \%$ humidity environment, the two-color method had potential to provide greater measurement accuracy than the empirical equations.
\end{abstract}

\section{Keywords}

Two-Color Method, Length Measurement, Sensitivity Coefficient, Uncertainty, Empirical Equations

\section{Introduction}

Meter, the unit of length, is defined in vacuum. However, measurements of length are often carried out in air, which presents some problems. Let us assume that we want to compare two geometric distances $G_{1}$ and $G_{2}$. These two distances are measured in air as $L_{1}=G_{1} \times n_{1}$ and $L_{2}=G_{2} \times n_{2}$, where $n_{1}$ and $n_{2}$ are the refractive index of air (RIA). In the absence of a relationship between $n_{1}$ and $n_{2}$, it is not possible to determine which of $G_{1}$ and $G_{2}$ is greater only by judging the magnitude relationship between $L_{1}$ and $L_{2}$. To solve this problem, the influence of RIA must be eliminated.

One approach to obtaining the value of RIA is to use empirical equations [1]-[4]. With $n$ obtained, an estimate of the geometric distance $G=L / n$ can be calculated. The estimated geometric distance can be used for comparison. The empirical equations are used to compensate for the RIA under two assumptions. First, environmental parameters (namely, temperature, pressure, and humidity) can be measured. Second, a measured environmental parameter is a good reproduction of that parameter along the optical path, meaning that a measured en-

\footnotetext{
${ }^{*}$ Corresponding author.
}

How to cite this paper: Wei, D., Takamasu, K. and Matsumoto, H. (2016) Is the Two-Color Method Superior to Empirical Equations in Refractive Index Compensation? Optics and Photonics Journal, 6, 8-13. 
vironmental parameter is an average value over time and space. In other words, both the spatial distribution of environmental parameters and the time-delay of measurement equipment can be ignored. These assumptions are valid only if the measurement is performed in a closed environment (e.g., a well-controlled laboratory or underground tunnel with limited variation in environmental parameters).

Another approach to suppressing the influence of RIA is to apply the two-color method, which was first proposed by Bender and Owens [5] to compensate for the inhomogeneous disturbances of the RIA in an open environment. The core concept of the two-color method is to use a measured length difference between two colors (frequencies) to render length measurements less sensitive to changes in the RIA.

Recently, high-precision length measurements based on fem to second optical frequency comb (FOFC) have been carried out (e.g., [6] [7]). To compensate for the RIA, FOFC-based RIA measurements [8] [9] and FOFCbased two-color method experiments [10]-[12] have also been performed. Minoshima's group performed a twocolor method experiment in a well-controlled environment and found an agreement between RIA compensation based on the empirical equations and that of two-color method with a standard deviation of $3.8 \times 10^{-11}$ throughout hours [13]. They also suggested that the accuracy provided by the empirical equations may be improved by the two-color method.

One question arises naturally: theoretically, is the two-color method superior to the empirical equations in RIA compensation? We employed a numerical approach to investigate this possibility.

\section{Methods}

\subsection{Refraction Index Compensation by Empirical Equations}

The distance between two points measured in air is an optical distance $L_{\text {air }}$. An estimate of the geometric distance $G_{\text {est } \_\lambda}$ in vacuum and the optical distance has the following relationship.

$$
G_{\text {est_ } \lambda}=L_{\text {air }} / n
$$

where $n$ represents the RIA. By applying the law of propagation of uncertainty [14] [15] to Equation (1), we obtain the uncertainty of length in vacuum.

$$
u\left(G_{\text {est_ } \_}\right)^{2}=\left\{[u(n) / n] \times G_{\text {est_ } \lambda}\right\}^{2}+\left\{\left[u\left(L_{\text {air_1 } 1}\right) / L_{\text {air_ } \_}\right] \times G_{\text {est_ } \lambda}\right\}^{2}
$$

where $u(x)$ denotes the uncertainty of variable $x$. The first and second terms of the right-hand side of Equation (2) are the uncertainty due to the refractive index and the length measurement, respectively. These two are defined as follows, respectively.

$$
\begin{gathered}
u_{n}\left(G_{\text {est } \_}\right)=[u(n) / n] \times G_{\text {est_ } \_} \\
u_{L}\left(G_{\text {est_ } \_}\right)=\left[u\left(L_{\text {air_1 }}\right) / L_{\text {air_1 } 1}\right] \times G_{\text {est_ } \_}
\end{gathered}
$$

The uncertainty of refractive index can be evaluated by the following equation [16] [17].

$$
u(n)=\sqrt{K_{\mathrm{T}_{0}}^{2} u^{2}\left(T_{0}\right)+K_{\mathrm{P}_{0}}^{2} u^{2}\left(P_{0}\right)+K_{\mathrm{H}_{0}}^{2} u^{2}\left(H_{0}\right)}
$$

where $u(T), u(P)$, and $u(H)$ are the uncertainties of the instrument for measuring temperature $T$, barometric pressure $P$, and humidity $H$, respectively. $K_{\mathrm{T}}, K_{\mathrm{P}}$, and $K_{\mathrm{H}}$ are sensitivity coefficients and defined as follows.

$$
K_{\mathrm{T}_{0}}=(d n / d T)_{T_{0}}, K_{\mathrm{P}_{0}}=(d n / d P)_{P_{0}}, K_{\mathrm{H}_{0}}=(d n / d H)_{H_{0}}
$$

where $(d n / d T)_{T_{0}}$ is the derivative of function $\mathrm{y}=n(T, P, H)$ at $T=T_{0}$. The definitions are similar for $(d n / d P)_{P_{0}}$ and $(d n / d H)_{H_{0}}$.

\subsection{Refraction Index Compensation by Two-Color Method}

The distances between two points measured in air by using different wavelengths are optical distances $L_{\text {air_1 }}$ and $L_{\text {air_2 } 2}$. An estimate of the geometric distance $G_{\text {est_2 } 2 \lambda}$ from these two optical distances can be obtained as follows: 


$$
G_{\text {est_2i }}=L_{\text {ai__2 }}-A \times\left(L_{\text {air_2 }}-L_{\text {air_1 }}\right)
$$

where $A$ is the so-called $A$-factor defined as

$$
A=\left[n\left(\lambda_{\text {vac } \_2}, T, P, H\right)-1\right] /\left[n\left(\lambda_{\text {vac_2 }}, T, P, H\right)-n\left(\lambda_{\text {va_ } \_1}, T, P, H\right)\right]
$$

Equation (7) can be rewritten as follows.

$$
G_{\text {est_2 } 2 \lambda}=A \times L_{\text {air_1 }}+(1-A) \times L_{\text {air_2 }}
$$

By applying the law of propagation of uncertainty to Equation (9), we have

$$
u\left(G_{\text {est_2 } 2}\right)^{2}=u\left(A \times L_{\text {air_1 } 1}\right)^{2}+u\left[(1-A) \times L_{\text {air_2 }}\right]^{2}
$$

The uncertainties of the first and second terms of the right-hand side of Equation (10) are, respectively,

$$
\begin{gathered}
{\left[u\left(A \times L_{\text {air_1 }}\right) / A \times L_{\text {air_1 }_{1}}\right]^{2}=[u(A) / A]^{2}+\left[u \left(L_{\text {air_1 } \left.\left._{1}\right) / L_{\text {air_1 }}\right]^{2}}\right.\right.} \\
\left\{u\left[(1-A) \times L_{\text {air_2 }_{2}}\right] /\left[(1-A) \times L_{\text {air_2 }_{2}}\right]\right\}^{2}=[u(1-A) /(1-A)]^{2}+\left[u\left(L_{\text {air_2 }_{2}}\right) / L_{\text {air_2 }}\right]^{2}
\end{gathered}
$$

Because we have $u(1-A)^{2}=u(1)^{2}+u(A)^{2}=u(A)^{2}$, Equation (12) can be rewritten as follows.

$$
\left\{u\left[(1-A) \times L_{\text {air_2 }}\right] /\left[(1-A) \times L_{\text {air_2 }}\right]\right\}^{2}=[u(A) /(1-A)]^{2}+\left[u\left(L_{\text {air_2 }}\right) / L_{\text {air_2 }}\right]^{2}
$$

By substituting Equations (11) and (13) into Equation (10), we obtain

$$
u\left(G_{\text {est_2 } 2 \lambda}\right)^{2}=\left[u(A) \times L_{\text {air_1 }}\right]^{2}+\left[u\left(L_{\text {air_1 } 1}\right) \times A\right]^{2}+\left[u(A) \times L_{\text {air_2 }}\right]^{2}+\left[u\left(L_{\text {air_2 }}\right) \times(1-A)\right]^{2}
$$

The first and third terms of the right-hand side of Equation (14) are the uncertainty due to the A-factor, and the second and fourth terms are the uncertainty due to the length measurement. These two are defined as follows, respectively.

$$
\begin{gathered}
u_{A}\left(G_{\text {est_2 } 2 \lambda}\right)=\sqrt{\left[u(A) \times L_{\text {air_1 }}\right]^{2}+\left[u(A) \times L_{\text {ai__2 }}\right]^{2}} \\
u_{L}\left(G_{\text {est_2 } 2}\right)=\sqrt{\left[u\left(L_{\text {air_1 }}\right) \times A\right]^{2}+\left[u\left(L_{\text {air_2 }}\right) \times(1-A)\right]^{2}}
\end{gathered}
$$

The uncertainty of $A$-factor is as follows.

$$
u(A)=\sqrt{K_{\mathrm{A}_{-} \mathrm{T}_{0}}^{2} u^{2}\left(T_{0}\right)+K_{\mathrm{A} \_\mathrm{P}_{0}}^{2} u^{2}\left(P_{0}\right)+K_{\mathrm{A}_{-} \mathrm{H}_{0}}^{2} u^{2}\left(H_{0}\right)}
$$

where $K_{\mathrm{A}_{-} \mathrm{T}}, K_{\mathrm{A}_{-} \mathrm{P}}$, and $K_{\mathrm{A}_{\_} \mathrm{H}}$ are the sensitivity coefficients of the $A$-factor and are defined as follows.

$$
K_{\mathrm{A}_{-} \mathrm{T}_{0}}=(d A / d T)_{T_{0}}, K_{\mathrm{A}_{-} \mathrm{P}_{0}}=(d A / d P)_{P_{0}}, K_{\mathrm{A}_{-} \mathrm{H}_{0}}=(d A / d H)_{H_{0}}
$$

where $(d A / d T)_{T_{0}}$ is the derivative of function $\mathrm{y}=A(T, P, H)$ at $T=T_{0}$. The definitions are similar for $(d A / d P)_{P_{0}}$ and $(d A / d H)_{H_{0}}$.

\subsection{Comparison of Empirical Equations and Two-Color Method}

In Equation (4), the uncertainty due to the length measurement is multiplied by the factor $G_{\text {est_ } \lambda} / L_{\text {air_1 }}=n \approx 1$. In Equation (16), the uncertainty due to the length measurement is multiplied by two factors, $A$ and $1-A$. Normally, their orders are several tens. If the two wavelengths used in the two-color method are $780 \mathrm{~nm}$ and $1560 \mathrm{~nm}$, then $A \approx 141$ and $1-A \approx-140$. By comparing the magnitudes of Equation (4) and Equation (16), we understand that only when the condition

$$
\left[u_{A}\left(G_{\text {est_2 } 2 \lambda}\right)\right]^{2}<\left[u_{n}\left(G_{\text {est_ } \_}\right)\right]^{2}
$$

is satisfied, the two-color method can be shown to obtain measurements with a smaller error than that of the empirical equations. We performed numerical calculations to check whether Equation (19) is feasible.

\section{Numerical Calculations}

We used the following parameters for simulation. By referring to Ref. [18], we employed $780.0 \mathrm{~nm}$ and 1560.0 
$\mathrm{nm}$ as the two wavelengths. We used the equations for the phase refractive index given in Ref. [4]. Because of the limit on the length of this paper, we only considered the Edlén empirical equations in this study. In the Edlén empirical equations [2]-[4], the RIA can be derived from the wavelength in vacuum $\lambda$, temperature $T$, barometric pressure $P$, and humidity $H$ as $\mathrm{n}=f(\lambda, T, P, H)$. The formula used to perform the calculations can be easily accessed via the internet [4]. In the following, we only consider the phase refractive index. The group refractive index can be treated in the same way.

On the basis of Equations (6) and (18), we calculated the change in the sensitivity coefficients when environmental parameters change in a realistic range $\left(T \in[10,30]{ }^{\circ} \mathrm{C}, P \in[90,115] \mathrm{kPa}, H=0 \%\right)$. The calculations of the derivative of each refractive index have been validated in Ref. [19]. The same procedure was used in this study for calculating the derivative of the $A$-factor. After obtaining an expression for the sensitivity coefficients by substituting numerical values, the values of sensitivity coefficients were calculated.

As shown in Figure 1, when $H=0 \%$, the sensitivity coefficient of the $A$-factor is smaller than that of the refractive indices. This result, i.e., the $A$-factor can be considered as a function of just two wavelengths only when the humidity is $0 \%$, is consistent with the results of previous studies [10] [11] [13] [20]-[24].

On the basis of Equations (3) and (15), we calculated the uncertainties due to the $A$-factor and refractive indices, respectively. The geometric distance $G$ was set to $1 \mathrm{~m}$. We assumed that $u(T)=0.1^{\circ} \mathrm{C}$ and $u(P)=0.01 \mathrm{kPa}$ on the basis of using a thermometer (Testo 735, Testo) and a barometer (VR-18, Sunoh), respectively. These two are commercially available for us.

Figure 2 shows that $u_{A}\left(G_{\text {est_2 } 2}\right)<u_{n}\left(G_{\text {est_ } \lambda}\right)$. This result means that in a $0 \%$ humidity environment, the twocolor method has potential to provide greater measurement accuracy than the empirical equations. Note that the orders of values shown in Figure 2 were affected by the sensitivity coefficients of environmental parameters and the uncertainties of the instrument for measuring environmental parameters. A detailed uncertainty analysis in an environment where the humidity is not $0 \%$ will be reported in another paper.

\section{Conclusion}

We analyzed the uncertainties of length conversion based on the Edlén empirical equations and the two-color

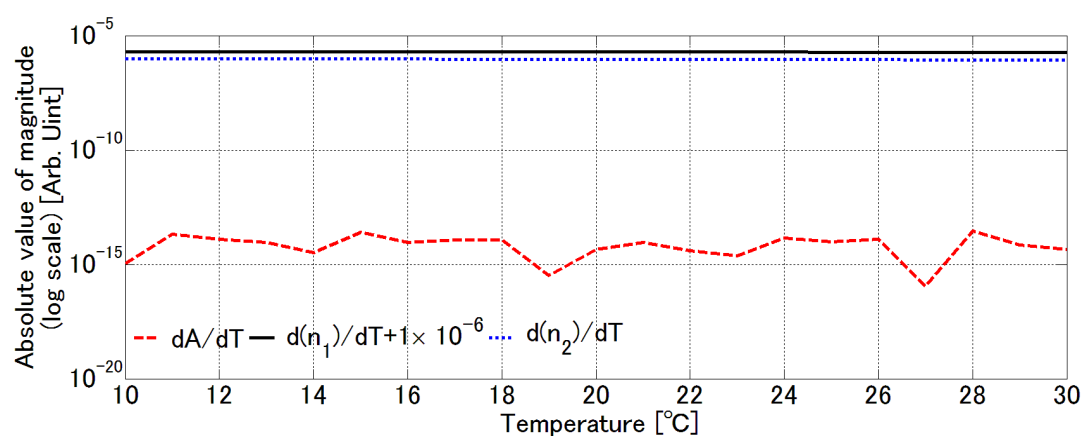

(a)

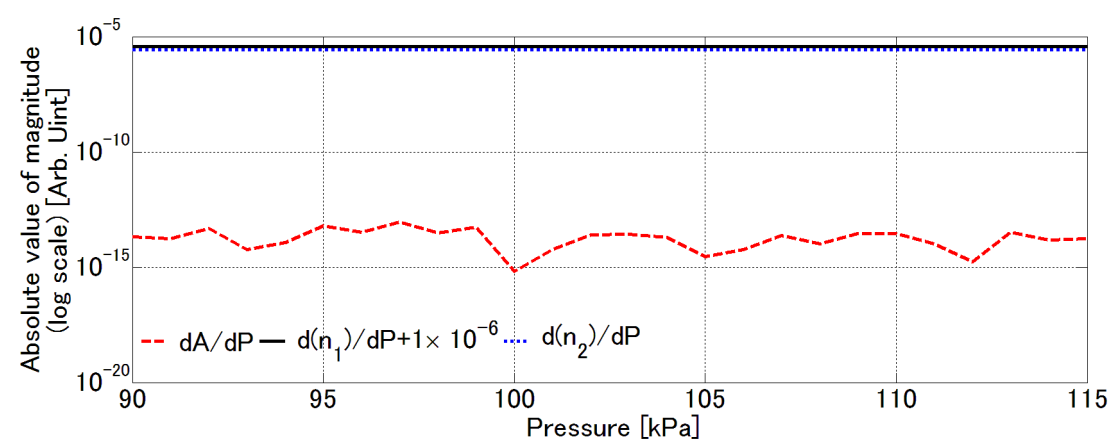

(b)

Figure 1. Change in sensitivity coefficients of $A$-factor and refractive indices with (a) temperature when $P=101.325 \mathrm{kPa}$ and $H=0 \%$ and (b) pressure when $T=20^{\circ} \mathrm{C}$ and $H=0 \%$. 


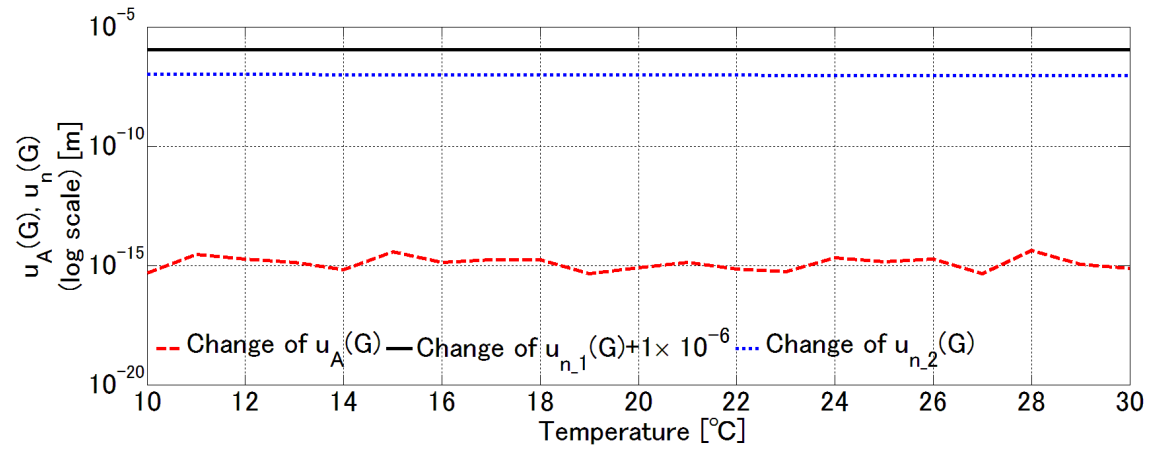

(a)

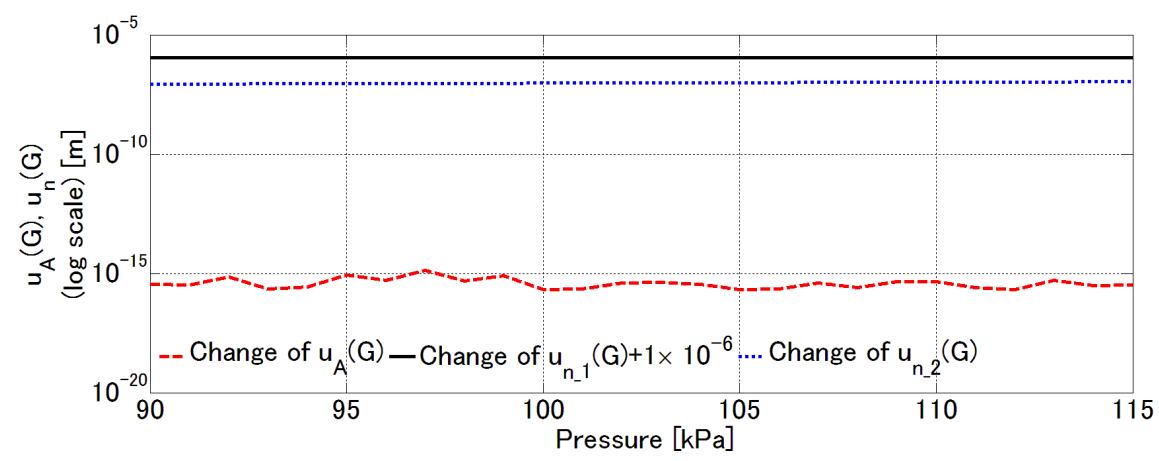

(b)

Figure 2. Change in uncertainties due to $A$-factor and refractive indices with (a) temperature when $P=101.325 \mathrm{kPa}$ and $H=0 \%$ and (b) pressure when $T=20^{\circ} \mathrm{C}$ and $H=0 \%$.

method, in which the uncertainties due to length measurement and refractive index compensation were decomposed. Using numerical calculations of sensitivity coefficients of the A-factor and refractive indices of the environmental parameters, we found for the first time that in a realistic environmental parameter range $(T \in[10,30]$ ${ }^{\circ} \mathrm{C}, P \in[90,115] \mathrm{kPa}, H=0 \%$ ), the uncertainty of the two-color method due to the $A$-factor was smaller than that of the empirical equations due to refractive indices. This result suggests that in a $0 \%$ humidity environment, the two-color method has potential to provide greater measurement accuracy than the empirical equations, with the cooperation of suppressing the uncertainties of length measurements (compared with uncertainties of refractive index compensation) to a negligible level. The findings of this study provide a better insight into the twocolor method, and will create opportunities for further development of application of this method.

\section{Acknowledgements}

This research work was partially financially supported by a grant (R1501) from the Mitutoyo Association for Science and Technology.

\section{References}

[1] Ciddor, P.E. (1996) Refractive Index of Air: New Equations for the Visible and Near Infrared. Appl. Opt, 35, 1566-1573. http://dx.doi.org/10.1364/ao.35.001566

[2] Birch, K.P. and Downs, M.J. (1993) An Updated Edlén Equation for the Refractive Index of Air. Metrologia, $30,155$. http://dx.doi.org/10.1088/0026-1394/30/3/004

[3] Bengt, E. (1966) The Refractive Index of Air. Metrologia, 2, 71. http://dx.doi.org/10.1088/0026-1394/2/2/002

[4] Stone, J.A. and Zimmerman, J.H. Refractive Index of Air Calculator. http://emtoolbox.nist.gov/Wavelength/Edlen.asp

[5] Bender, P.L. and Owens, J.C. (1965) Correction of Optical Distance Measurements for the Fluctuating Atmospheric Index of Refraction. J. Geophys. Res, 70, 2461-2462. http://dx.doi.org/10.1029/JZ070i010p02461

[6] Coddington, I., Swann, W.C., Nenadovic, L. and Newbury, N.R. (2009) Rapid and Precise Absolute Distance Mea- 
surements at Long Range. Nat Photon, 3, 351-356. http://dx.doi.org/10.1038/nphoton.2009.94

[7] Lee, J., Kim, Y.-J., Lee, K., Lee, S. and Kim, S.-W. (2010) Time-of-Flight Measurement with Femtosecond Light Pulses. Nat Photon, 4, 716-720. http://dx.doi.org/10.1038/nphoton.2010.175

[8] Zhang, J., Lu, Z.H. Menegozzi, B. and Wang, L.J. (2006) Application of Frequency Combs in the Measurement of the Refractive Index of Air. Rev. sci. instrum, 77, 083104-083105. http://dx.doi.org/10.1063/1.2239036

[9] Zhang, J., Lu, Z.H. and Wang, L.J. (2007) Precision Measurement of the Refractive Index of Carbon Dioxide with a Frequency Comb. Opt. Lett, 32, 3212-3214. http://dx.doi.org/10.1364/OL.32.003212

[10] Minoshima, K. and Matsumoto, H. (2000) High-Accuracy Measurement of 240-m Distance in an Optical Tunnel by use of a Compact Femtosecond Laser. Appl. Opt, 39, 5512-5517. http://dx.doi.org/10.1364/AO.39.005512

[11] Meiners-Hagen, K. and Abou-Zeid, A. (2008) Refractive Index Determination in Length Measurement by two-Colour Interferometry. Meas. Sci. Technol, 19, 084004. http://dx.doi.org/10.1088/0957-0233/19/8/084004

[12] Kang, H.J., Chun, B.J., Jang, Y.-S., Kim, Y.-J. and Kim, S.-W. (2015) Real-Time Compensation of the Refractive Index of Air in Distance Measurement. Opt. Express, 23, 26377-26385. http://dx.doi.org/10.1364/OE.23.026377

[13] Wu, G., Arai, K., Takahashi, M., Inaba, H. and Minoshima, K. (2013) High-Accuracy Correction of Air Refractive Index by Using Two-Color Heterodyne Interferometry of Optical Frequency Combs. Meas. Sci. Technol, 24, 015203. http://dx.doi.org/10.1088/0957-0233/24/1/015203

[14] Coleman, H.W. and Steele, W.G. (1999) Experimentation and Uncertainty Analysis for Engineers, A Wiley Interscience publication. Wiley.

[15] Walter, B. Maurice, G.C. and Peter, M.H. (2006) Evolution of the "Guide to the Expression of Uncertainty in Measurement”. Metrologia, 43, S161. http://dx.doi.org/10.1088/0026-1394/43/4/S01

[16] Kevin, H. (2013) Handbook of Optical Dimensional Metrology, Series in Optics and Optoelectronics. Taylor \& Francis.

[17] Ellis, J.D. (2014) Field Guide to Displacement Measuring Interferometry, The Field Guide Series. SPIE, Bellingham. http://dx.doi.org/10.1117/3.1002328

[18] Wu, G., Takahashi, M., Arai, K., Inaba, H. and Minoshima, K. (2013) Extremely High-Accuracy Correction of Air Refractive Index Using Two-Colour Optical Frequency Combs. Sci. Rep, 3.

[19] Wei, D. and Aketagawa, M. (2015) Uncertainty in Length Conversion due to Change of Sensitivity Coefficients of Refractive Index. Opt. Commun, 345, 67-70. http://dx.doi.org/10.1016/j.optcom.2015.01.070

[20] Ishida, A. (1989) Two-Wavelength Displacement-Measuring Interferometer Using Second-Harmonic Light to Eliminate Air-Turbulence-Induced Errors. Jpn. J. Appl. Phys, 28, L473. http://dx.doi.org/10.1143/jjap.28.1473

[21] Matsumoto, H. and Honda, T. (1992) High-Accuracy Length-Measuring Interferometer Using the two-Colour Method of Compensating for the Refractive Index of Air. Meas. Sci. Technol, 3, 1084. http://dx.doi.org/10.1088/0957-0233/3/11/011

[22] Matsumoto, H., Zhu, Y., Iwasaki, S. and Oishi, T. (1992) Measurement of the Changes in Air Refractive Index and Distance by Means of a Two-Color Interferometer. Appl. Opt, 31, 4522-4526. http://dx.doi.org/10.1364/AO.31.004522

[23] Golubev A.N. and Chekhovsky, A.M. (1994) Three-Color Optical Range Finding. Appl. Opt, 33, 7511-7517. http://dx.doi.org/10.1364/AO.33.007511

[24] Minoshima, K., Arai, K. and Inaba, H. (2011) High-Accuracy Self-Correction of Refractive Index of Air Using Two-Color Interferometry of Optical Frequency Combs. Opt. Express, 19, 26095-26105. http://dx.doi.org/10.1364/OE.19.026095 


\section{Submit or recommend next manuscript to SCIRP and we will provide best service for you:}

Accepting pre-submission inquiries through Email, Facebook, LinkedIn, Twitter, etc.

A wide selection of journals (inclusive of 9 subjects, more than 200 journals)

Providing 24-hour high-quality service

User-friendly online submission system

Fair and swift peer-review system

Efficient typesetting and proofreading procedure

Display of the result of downloads and visits, as well as the number of cited articles

Maximum dissemination of your research work

Submit your manuscript at: http://papersubmission.scirp.org/ 